\title{
New Frontiers for Fairer Breast Cancer Care in a Globalized World
}

(1) Didier Verhoeven ${ }^{1}$, (1) Claudia Allemani², (1) Cary Kaufman³, (1) Sabine Siesling ${ }^{4}$, (1) Manuela Joore ${ }^{5}$, (D) Etienne Brain ${ }^{6}$, (D) Mauricio Magalhães Costa $^{7}$

${ }^{1}$ Department of Medical Oncology, University of Antwerp, AZ Klina, Brasschaat, Belgium

${ }^{2}$ Department of Non-Communicable Disease Epidemiology, London School of Hygiene and Tropical Medicine, Cancer Survival Group, London, UK ${ }^{3}$ Department of Surgery, University of Washington, Washington, USA

${ }^{4}$ Department of Health Technology and Services Research, Technical Medical Centre, University of Twente, Enschede, Netherlands

${ }^{5}$ Department of Clinical Epidemiology and Medical Technology Assessment, Care and Public Health Research Institute, Maastricht University Medical Centre, Maastricht, Netherlands

${ }^{6}$ Department of Medical Oncology, Institut Curie, Paris \& Saint-Cloud, France

${ }^{7}$ Breast Center of Americas Integrated Oncology Center, Rio de Janeiro, Brazil

\section{ABSTRACT}

In early 2020, the book "Breast cancer: Global Quality Care" was published by Oxford University Press. In the year since then, publications, interviews (by ecancer), presentations, webinars, and virtual congress have been organized to disseminate further the main message of the project: "A call for Fairer Breast Cancer Care for all Women in a Globalized World." Special attention is paid to increasing the "value-based healthcare" putting the patient in the center of the care pathway and sharing information on high-quality integrated breast cancer care. Specific recommendations are made considering the local resource facilities. The multidisciplinary breast conference is considered "the jewel in the crown" of the integrated practice unit, connecting multiple specializations and functions concerned with patients with breast cancer. Management and coordination of medical expertise, facilities, and their interfaces are highly recommended. The participation of two world-leading cancer research programs, the CONCORD program and Breast Health Global Initiative, in this project has been particularly important. The project is continuously under review with feedback from the faculty. The future plan is to arrive at an openaccess publication that is freely available to all interested people. This project is designed to help ease the burden and suffering of women with breast cancer across the globe.

Keywords: Quality, global health, breast cancer, innovation, value

Cite this article as: Verhoeven D, Allemani C, Kaufman C, Siesling S, Joore M, Brain E, Magalháes Costa M. New Frontiers for Fairer Breast Cancer Care in a Globalized World. Eur J Breast Health 2021; 17(2): 86-94

\section{Key Points}

- Strategic planning for global breast cancer control requires an active surveillance of breast cancer incidence, stage at presentation, and survival through population-based cancer registries.

- The maintenance of cancer registries requires a political will, legislative action, and financial stability to sustain their critical activities over time.

- Improved breast cancer outcome is best achieved through systematic approaches such as prevention, early detection, prompt diagnosis, and effective cancer management, where coordinated multidisciplinary teamwork is pivotal to success.

- Value-based healthcare used patient-centric care models, through which an evidence-based, resource-appropriate care pathway defines the optimalquality integrated clinical practice.

- A value-based price threshold can guide the allocation of limited resources to achieve high-quality care.

- The regulation should ensure that cancer diagnostic and treatment innovations enter the market because of not only their potential benefit but also their demonstrated comparative cost-effectiveness. Decisions should not be based only on the results of traditional randomized controlled trials, but they should also include real-world data from population-based cancer registries and other sources.

- Breast cancer early detection through clinical downstaging is a prerequisite to mammographic screening.

- Governments must ensure that their health system is equitable and has the features required by human rights. 


\section{Introduction (Video 1)}

VideoLink1:https://www.youtube.com/watch?v=XDXBRtQQM68

In early 2020, the book "Breast Cancer: Global Quality Care" was published by Oxford University Press (1) (Figure 1). In August 2020, the article "Breast Cancer: Global Quality Care, Optimizing Care Delivery with Existing Financial and Personnel Resources" was published in ESMO-Open (2). On November 16 ${ }^{\text {th }}$, 2020, during the $4^{\text {th }}$ International Oncology Leadership Conference by the Mandrier Group, a virtual meeting was organized, involving key faculty members. They discussed new frontiers for achieving fair breast cancer care in a globalized world (Figure 2). In this article, we highlighted the main ideas and presented some recommendations. Recordings of the presentations can be found on the Senologic International Society website (www.sisbreast.org). Starting with a global vision, we tried finding solutions to identify the optimal quality of breast care, taking into account the local financial and organizational restrictions.
Many important aspects are involved, such as quality management, multidisciplinary care, research, economics, regional differences (city versus rural context), information technology, interactions between patients and physicians, and media. The generated ideas are the result of discussions between more than 100 experts from 25 countries in five continents. The project is continuously evolving, and the goal is to arrive at an open-access publication that is available to everybody, without borders.

\section{Global surveillance of cancer survival trends}

Population-based survival for patients diagnosed with breast cancer is a key measure of the overall effectiveness of the local health system in managing the disease. This indicator summarizes the final result of the efficiency of early diagnosis, screening, investigation, and treatment as well as the availability of resources and local organization for breast cancer care. Global surveillance of breast cancer survival and improvement of the situation are possible only

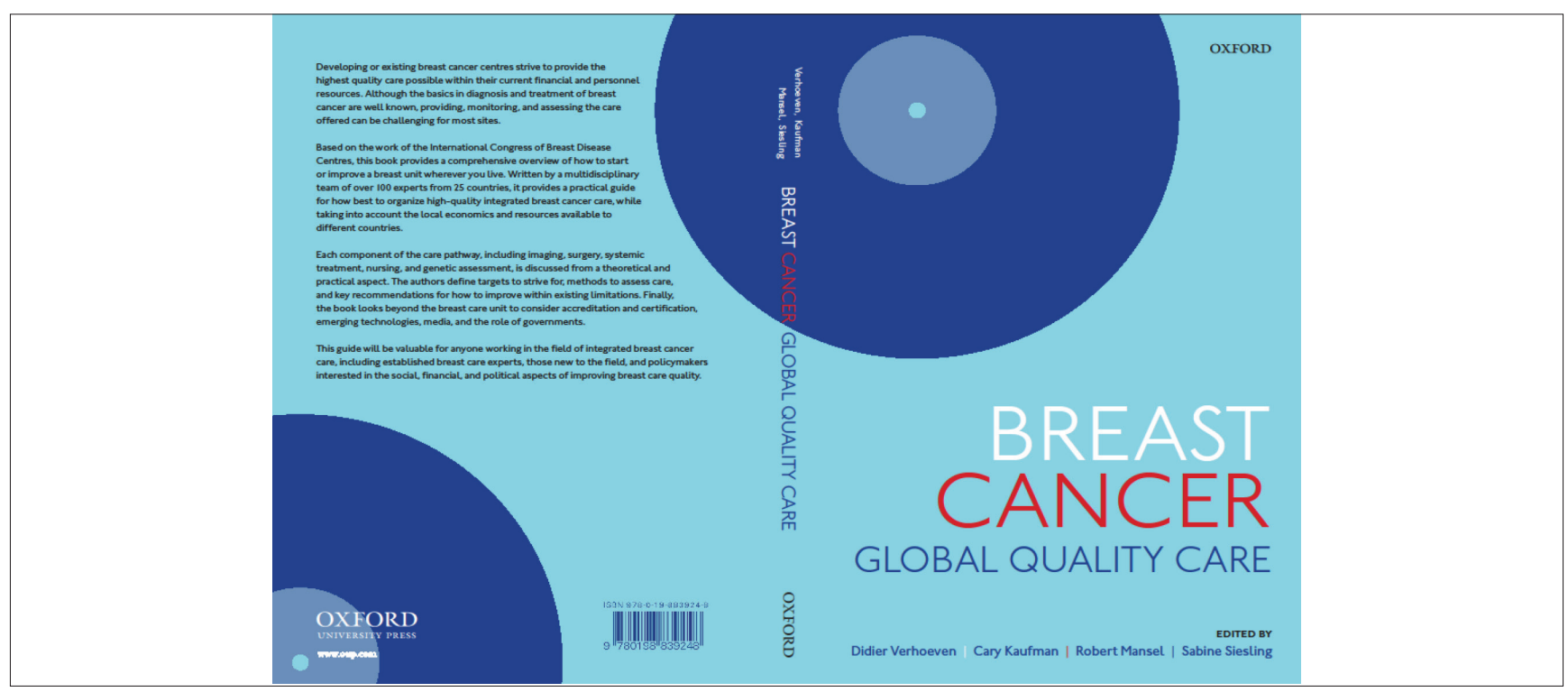

Figure 1. Breast Cancer: Global Quality Care

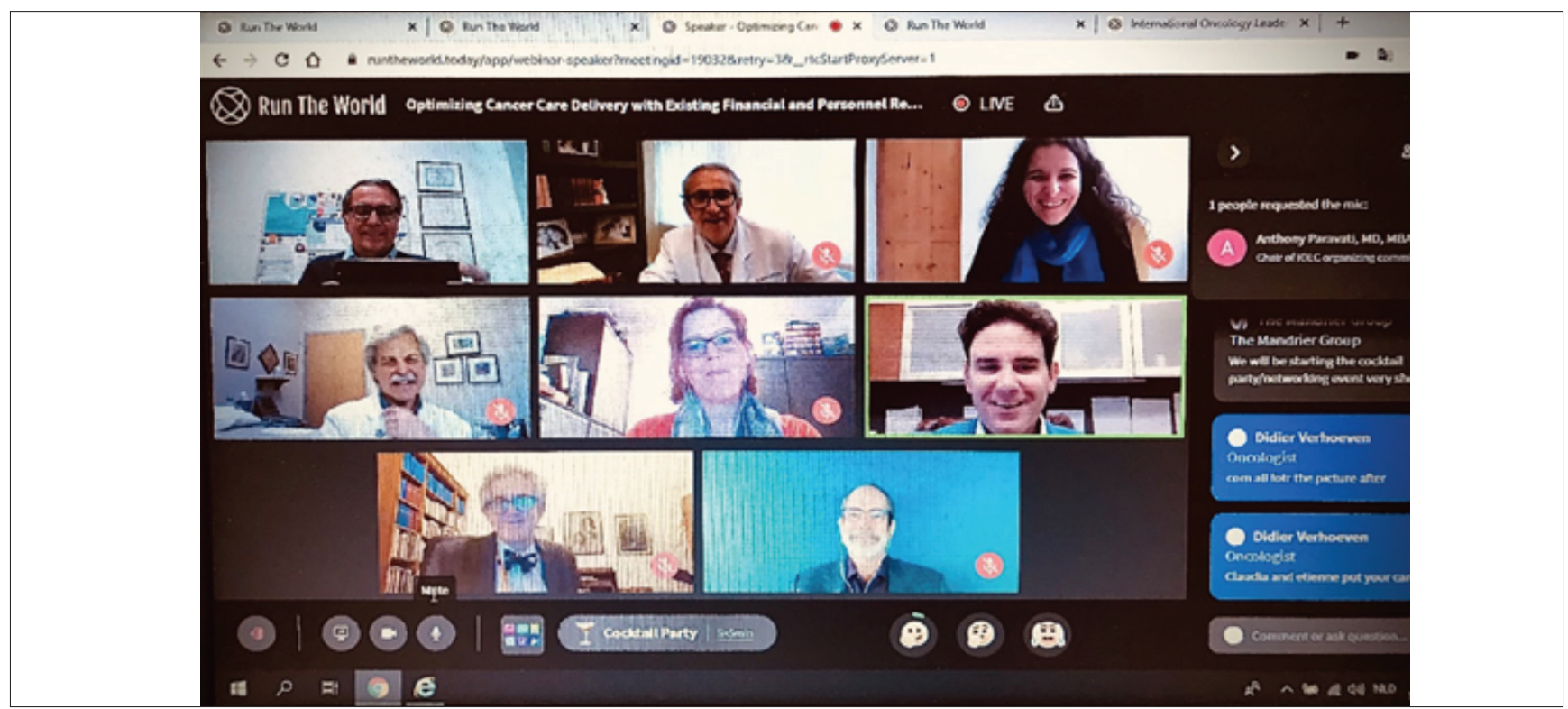

Figure 2. Participants of the virtual meeting (D. Verhoeven; M. Magalhães Costa; C. Allemani; C. Kaufman; S. Siesling; A. Paravati; E. Brain; B. Anderson; missing: M. Joore) 
if we focus on monitoring the trends (the late Dr. Tabaré Vazquez, Oncologist and President of Uruguay, World Cancer Leaders' Summit, 2010). Clinical trials measure the highest achievable survival for a selected group of patients, whereas public health data measure the average survival achieved by all patients with cancer. Raising awareness regarding persistent inequalities in accessing lifesaving breast cancer services can help reduce inequalities in survival. Global surveillance of breast cancer survival trends helps identify these disparities, which can impact policies and encourage actions to reduce them (3). The third cycle of the CONCORD program for global surveillance of cancer survival provided up-todate survival trends for 71 countries and territories, using data from 322 population-based cancer registries that cover a total population of nearly one billion people (4). For example, age-standardized fiveyear net-survival trends for breast cancer showed that even though survival has been increasing in all European countries over the 20-year period of 1995-2014, variability remains wide. Survival remains lower in Eastern Europe (Figure 3). These results have had an important impact on policies in different areas of the world. They impacted the following: national plans in England, France, and Poland; cancer control strategy in the European Union; survival data by state, race, and stage in the United States of America (USA) (5). Since 2017, survival estimates from CONCORD have also been officially recognized by the Organization of Economic Cooperation and Development (OECD) as one of the healthcare quality indicators for the 48 member or partner countries of OECD, and they are published in its Health at a Glance publication, www. oecd.org (6). These results also raise questions for further research. Worldwide surveillance of cancer survival trends is crucial to plan strategies for cancer control. Up-to-date data from cancer registries are essential to monitor worldwide cancer survival trends. Cancer registries need a political, legislative, and financial stable support to continue their key activities.

\section{Multidisciplinary Breast Conference (MBC): live versus virtual}

As knowledge and options have expanded in every discipline, multidisciplinary discussions have become mandatory in many countries due to their vital role in optimal patient management. The multidisciplinary breast conference (MBC) is the hub for the central exchange of knowledge at the individual patient and organizational levels to define regionally sensitive patient management. The simple criteria for a successful MBC include participants meeting regularly (usually weekly), attendance of all specialties, and integration of mutually-agreed-upon care guidelines or protocols (7) (Figure 4). $\mathrm{MBC}$ will frequently identify beneficial changes in management. Nevertheless, some obstacles have been identified. Time and location are inconvenient for some practices, and many cases are "not applicable to [my] specialty." In addition, many "routine" patients pose no challenge for providers, some patients need a re-discussion because of incomplete workups, and radiology and pathology specialists may complain of too much preparatory work.

To remove some of these barriers, $\mathrm{MBC}$ could be allowed to provide credits for continuing medical education, the most challenging cases could be discussed first, and improvements to the efficiency of patient flows must be organized. Moreover, the meetings should be supported by up-to-date technology, such as the availability of data (e.g., images) within the electronic health record and video conferences for consultants from a reference hospital. A simultaneous breakfast or lunch can be helpful in teambuilding.

The coronavirus disease-2019 (COVID-19) pandemic has brought both positive and negative changes to live meetings. Almost all MBCs are now virtual video meetings. This has caused the loss of personal interaction between clinicians, and $\mathrm{MBC}$ has become a more formal "business" conference. Using team meeting software programs has introduced many uncomfortable pauses, and choppy

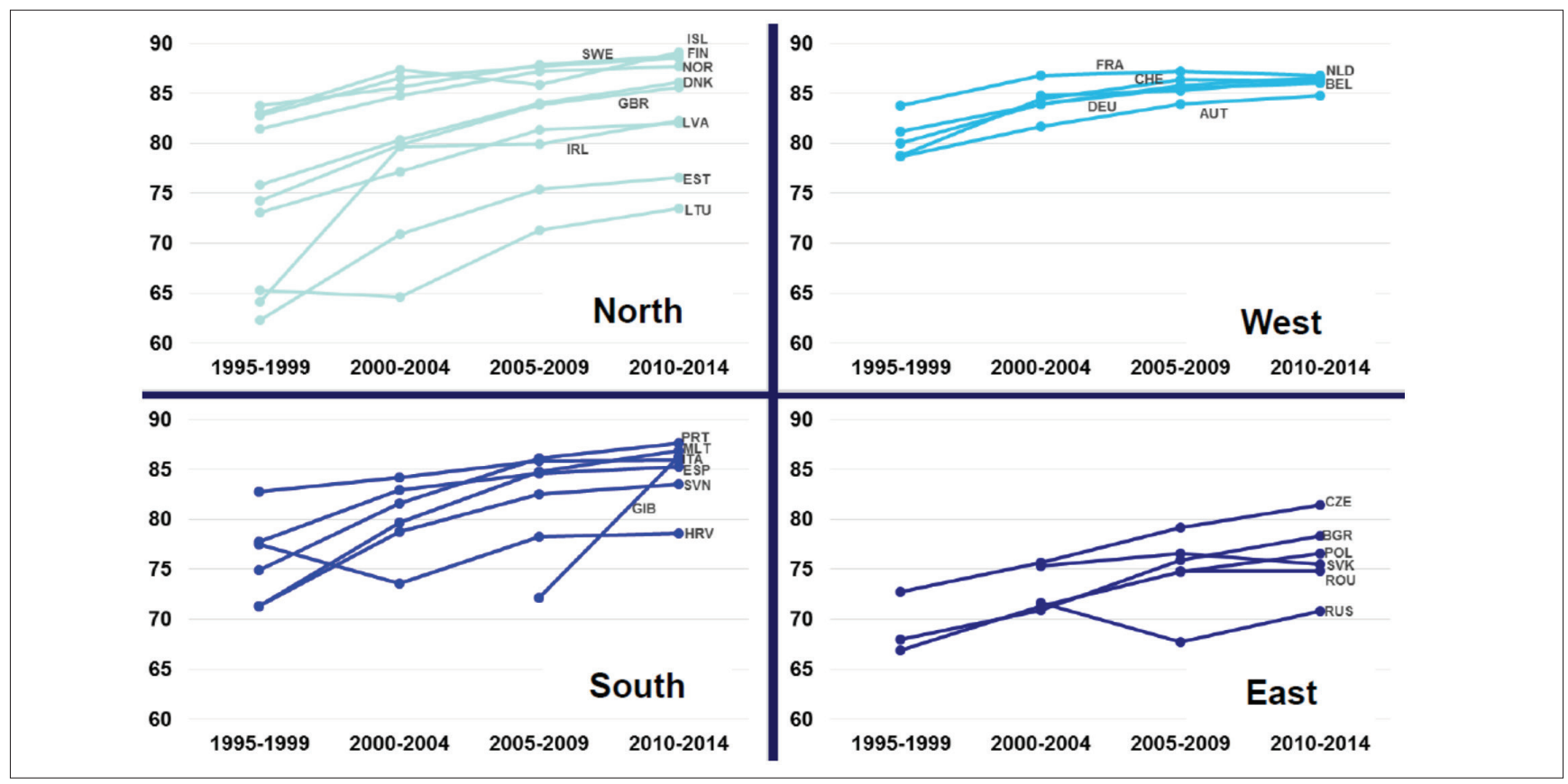

Figure 3. Breast cancer: age-standardized five-year net-survival (\%) trends in European countries, 1995-2014. [Allemani et al. 2018 (4)]

FRA: France; SWE: Sweden; GBR: Great Britain/United Kingdom; IRL: Ireland; ISL: Iceland; FIN: Finland; NOR: Norway; DNK: Denmark; LVA: Latvia; EST: Estonia; LTU: Lithuania; NDL: Netherlands; AUT: Austria; CHE: Switzerland; DEU: Germany; GIB: Gibraltar; PRT: Portugal; ESP: Spain; ITA: Italy; SVN: Slovenia; HRV: Croatia; POL: 
flow of discussion may occur due to "share screen" switching (Figure 5).

Nevertheless, some benefits are recognized. The meetings are easier to attend by saving travel time and improving access to patients' clinical data. The discussion can be held in COVID-safe environments with a more focused discussion and without distractions or side discussions.

Whether in-person or virtual, MBC remains the springboard for research and integrated treatment plans and the forum for second opinions and optimizing the management of patients with breast cancer. Although MBC will survive COVID-19, we are looking forward to meeting again in a live environment.

\section{Value-based healthcare: myth or reality?}

The value-based healthcare concept started with the book of Michael Porter and Elizabeth Taisberg: "Redefining Healthcare: Creating ValueBased Competition on Results" in 2006 (8). Value-based healthcare can be defined as the equation that puts patient-relevant outcomes in the numerator and cost per patient to achieve these outcomes in the denominator (Figure 6). Breast cancer care is costly, due to the rising incidence, increasing survival, and prevalence, with better treatment options. A complex disease such as breast cancer makes this vision even more relevant.

There is no such thing as "THE breast cancer patient." Frequently important variations in provided treatment are observed without proven benefit. An interesting example is the use of neoadjuvant chemotherapy in patients with breast cancer in Dutch hospitals. A large variation is observed, which is not related to the outcome or caseload volume of the hospital (9). Patients should be informed about their options and estimated harms and benefits and then decide, together with their treating physicians, which treatment is best according to their personal situation. The clinical and social factors should be considered. Moreover, all patient-relevant outcomes must be considered: survival and disease control reported by the cancer registries, perceived utility of care, and degree of health and distress, which can be reported by the patient-reported outcomes measures (PROMs) (https://www.ichom.org/portfolio/breast-cancer/) (10). An illustrative example is the increasing role of oncoplastic surgery for the "aesthetic breast cancer cure." With the current expectation of better survival, more attention has been turned to the cosmetic results of surgery and the opportunities to educate breast surgeons about these techniques (11). Nevertheless, although PROMs are becoming more important, making them feasible and useful in daily practice measurements must be done using a limited number of questions with direct feedback in the consultation room. Although some steps have been taken to make this a reality, in the future, more effort will be

\section{MBC - COVID-19 Changes}

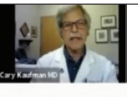

- The MBC has been the central exchange of ideas that maintains the breast center unit - the "heartbeat of the breast center" No Face-to-Face Meetings!!!

Zoom / Microsoft TEAMS / GoToMeeting / WebEx / Skype / Google Hangouts
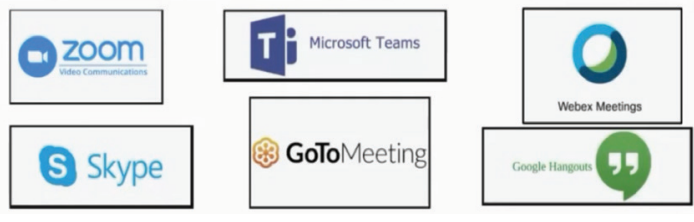

Figure 5. MBC in the times of COVID-19

MBC: Multidisciplinary Breast Conference; COVID-19: Coronavirus disease-2019

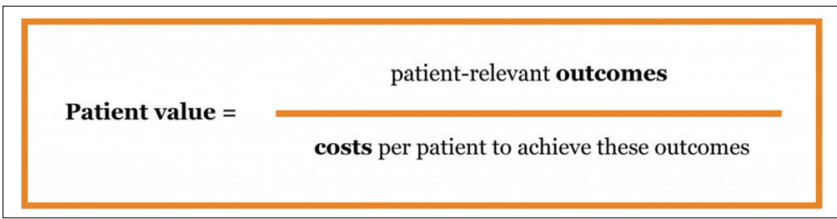

Figure 6. Definition of value-based healthcare

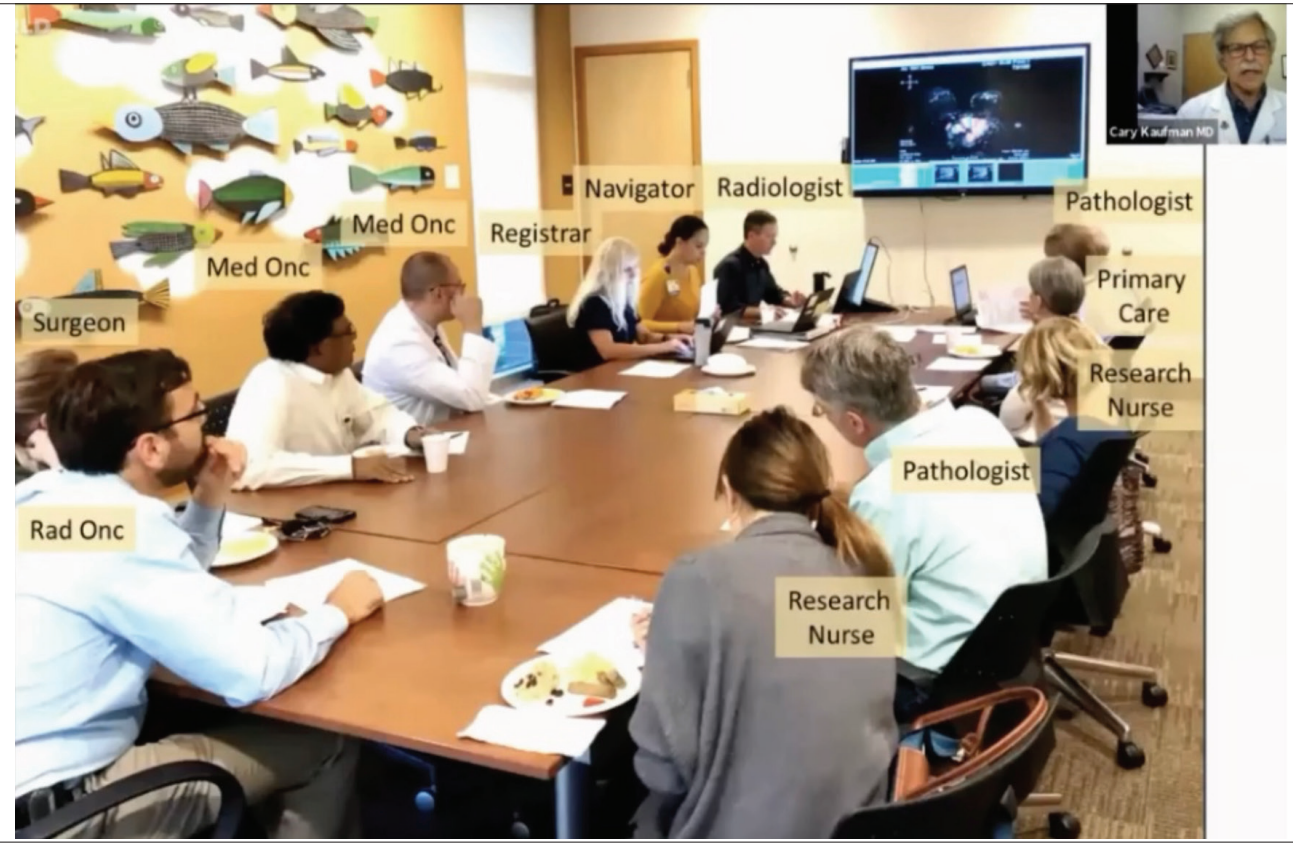

Figure 4. Interaction in MBC with participation of all disciplines at the Bellingham Regional Breast Center, Seattle, US MBC: Multidisciplinary Breast Conference; US: United States 
required to bring value to all patients in every country. The integration of healthcare quality improvement measures for health literacy, language access, and cultural access must be recommended (12).

\section{Maximizing patient value, considering the local resources}

Social healthcare expenditures, of which a considerable part is due to breast cancer care, are rising to levels that may not be sustainable in the future (13). Treatment costs of cancer are equally high both within and outside the healthcare system (14). Although these aspects are essential, the rising cost of cancer drugs is an important aspect in Europe (Figure 7). Economic evaluations of new and existing therapies can be used to inform budget allocations in a way that maximizes health outcomes and broaden the values to the patient. It is increasingly recognized that personalized care can offer more value for patients and at the same time provide value for money. It is timely that current clinical practice guidelines are revisited toward a more personalized approach, acknowledging the patient's voice and the burden of cost on society.

In low- and middle-income countries (LMIC) in Southeast Asia, approximately three of four new patients with breast cancer experience a financial catastrophe or die within one year after diagnosis. An advanced stage at diagnosis and lower socioeconomic status are significant determinants of this poor outcome. There is an urgent need for more resources to aid early detection and policies provided adequate financial protection from the treatment costs of cancer (15).

In an increasing number of jurisdictions, a threshold for an additional unit of health gain, expressed in a quality-adjusted life year, is used to

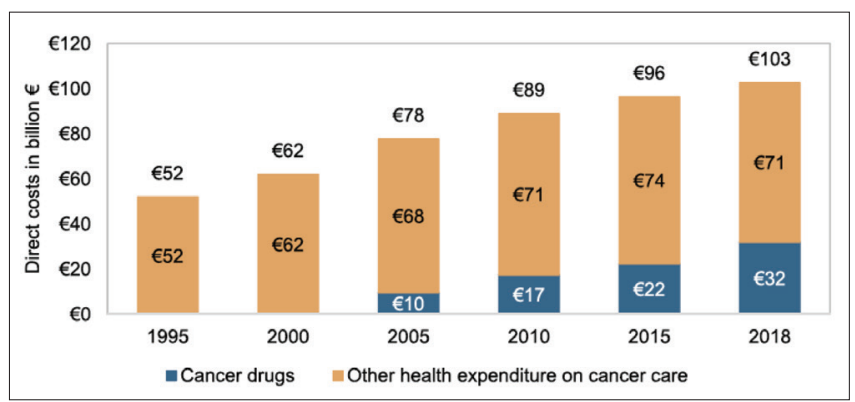

Figure 7. Direct costs of cancer in Europe (in billion) (14)

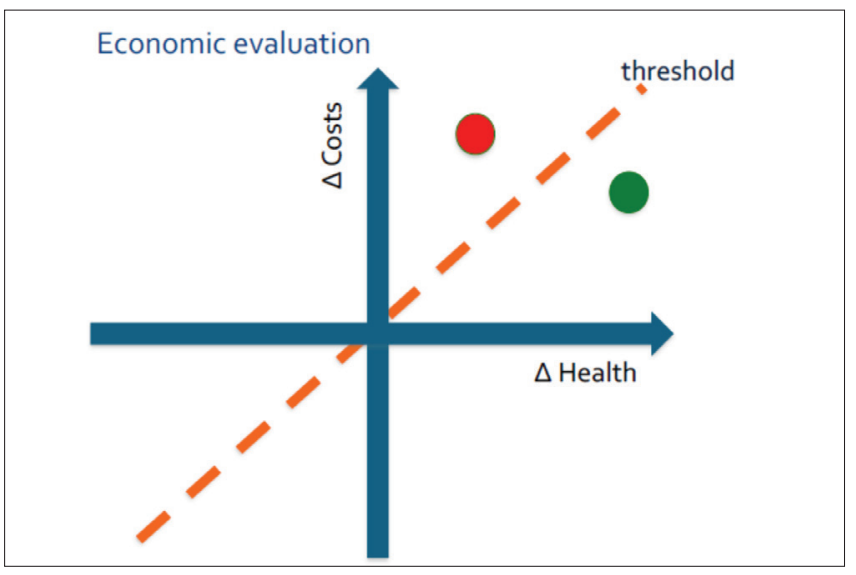

Figure 8. Cost in relation to health. The red and green dots show the economic evaluation of new interventions in relation to the determine whether a therapy provides value for money. In Figure 8, the threshold shows how effectiveness and costs of new interventions can be evaluated (16).

Improving the access to medicines by reducing the cost of cancer medications should involve trade agreements and flexibility of the Trade-Related Intellectual Property Rights (TRIPS). International patent law changes could mitigate cancer inequity in LMIC (17). The Doha Declaration affirmed the rights of states to implement policies to enable access to medicines to address the national health crisis and compulsory-license a patent for the production of generic drugs (18).

Innovations such as precision medicine may help reduce unneeded treatments, but they are associated with considerable initial costs and increasingly uncertain patient outcomes due to lack of clinical evidence. The costs hamper access: drugs do not cure anyone if patients cannot afford them. The uncertain outcomes pose a real risk to healthcare provision. The only viable road is to agree upon a broad value framework, encompassing both patient and social values. Such a framework is essential to guide a transparent, fair, and evidence-based decision making on a macrolevel. Setting a value-based price threshold can guide the allocation of our limited resources to achieve high-quality care. It can also be used to manage risks because of the uncertainty due to the lack of clinical evidence by engaging in managed entry agreements with pharmaceutical companies. This framework can also be used to support shared decision making. It integrates patient-reported outcomes, clinical evidence, and broader social considerations. It can be used to optimize personalized treatment strategies, considering the local resources.

\section{Bringing innovations to all patients with breast cancer}

Innovations and especially personalized medicine are not limited to drugs and are even sometimes more important but less popular in surgery and radiotherapy. Understanding the risk factors and causes of breast cancer must be promoted. An interesting initiative is the Sister Study in the USA prospectively examining environmental and familial risk factors for breast cancer in a cohort of 50,884 sisters of women who had breast cancer. A recent analysis suggested that, for example, substituting poultry for red meat could reduce cancer risk (19). The right design and endpoints are critical to making major advances in breast cancer care. These endpoints cannot include only the overall survival, progression-free survival, or response rate but it should also include health-related quality of life and PROMs, putting patients' values at the center of the research. Noninferiority compared with superiority, way of randomization, and relevance in the real world are critical considerations.

Clinical trials are mostly performed in younger patients, with less comorbidities and less organ dysfunction (20) (Figure 9). The recurrent discrepancy between data from trials and real world obtained from population-based cancer registries is important. The overall public health benefit must be addressed also with studies based on cancer registries, with no exclusive or partisan position. Moreover, the realworld data cannot wholly replace randomized clinical trials and require cautious interpretations to address the usual confounding factors and lack of control. In oncology, especially, the effects of the strategy of interest are often moderate or minor. In a time of a molecular tsunami with more than 100 oncogenic mutations, finding relevant ones is 
challenging. So, the design of the studies must be sound, including umbrella and basket trials (21).

In the future, important strides will come from de-escalation of treatment intensity, the neoadjuvant model (as a development accelerator), addressing better and more adequately the underserved patient populations and expectations of patients with cancer themselves (22).

Many challenges can hamper the availability of innovations.

The regulation should ensure that cancer innovation enters the market not on the promise of potential benefit but on actual demonstrated effectiveness. Post-marketing studies are helpful in preventing the endless inappropriate use of new treatments.

Innovation must be balanced considering the sustainability of healthcare budgets, and all health professionals have a responsibility to help achieve this balance. Independency and academism with international sharing can help deliver innovations and bring the best outcomes possible for patients within the limits of available and limited healthcare resources.

\section{Moving forward in a globalized world}

The Breast Health Global Initiative (BHGI) was founded to bring breast cancer care as a public health priority for all women worldwide, establishing resource-stratified guidelines (www.bhgi.info) (23). Recently, methodologies were described to implement this health priority into practice (24). One of the most important challenges is the early detection of breast cancer. Understanding the differences between screening and early diagnosis is key (www.who.int) (Figure 10).

Mammographic screening is unaffordable in most countries and does not apply to younger age groups. Pragmatically, in LMIC, early

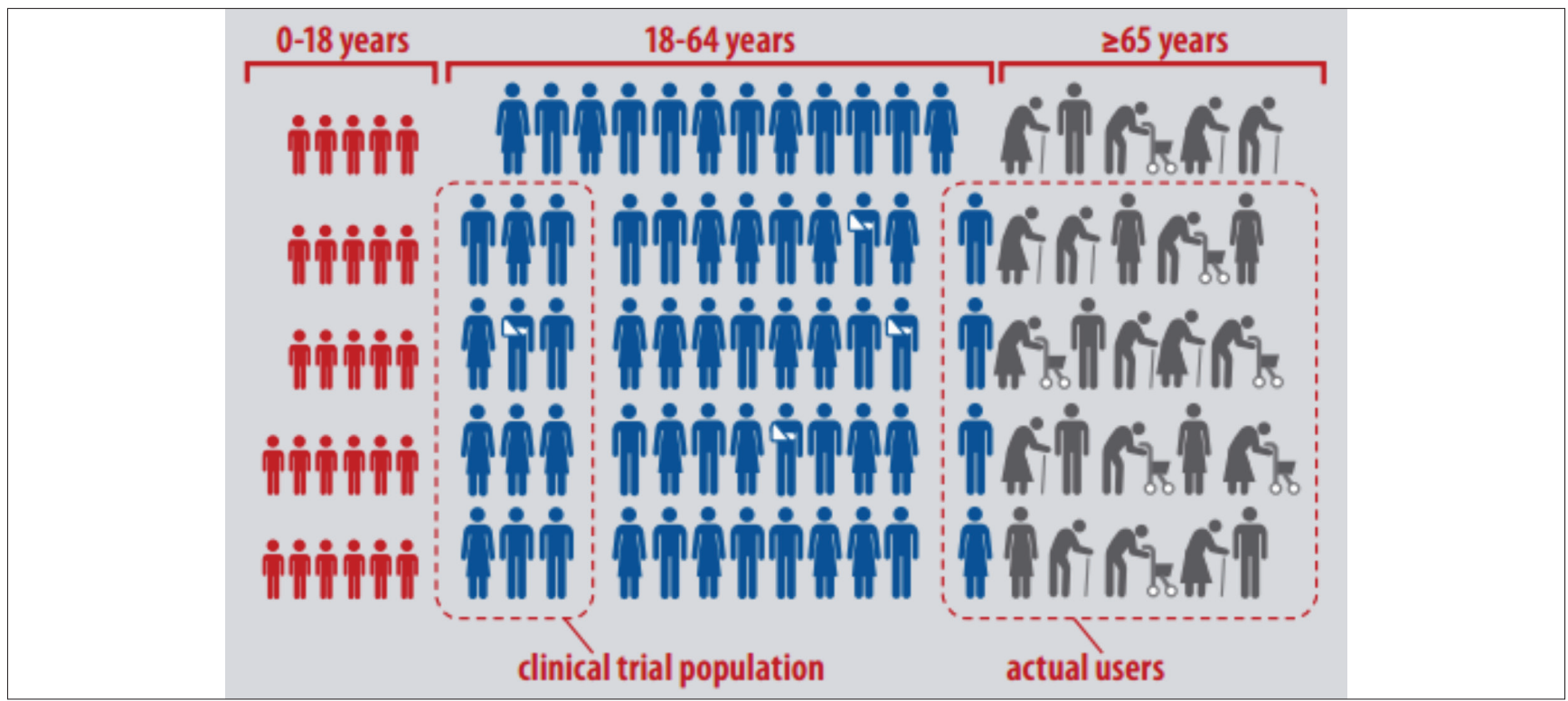

Figure 9. Trial population compared with real-life data. Actual users compared with the clinical trial population (Erna Beers, with permission, 20)

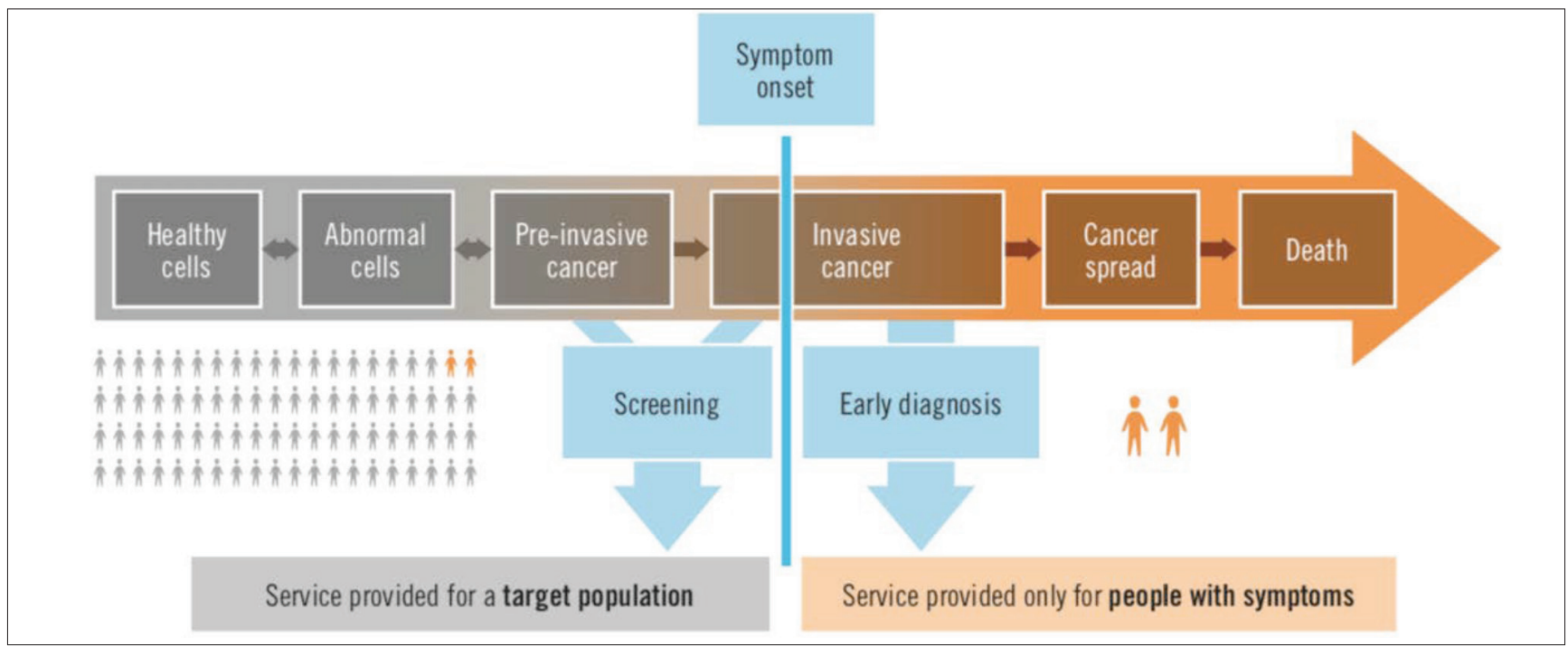

Figure 10. Understanding the difference between screening and early diagnosis (World Health Organization, reproduced from the Guide to Cancer Early Diagnosis, 2017) 


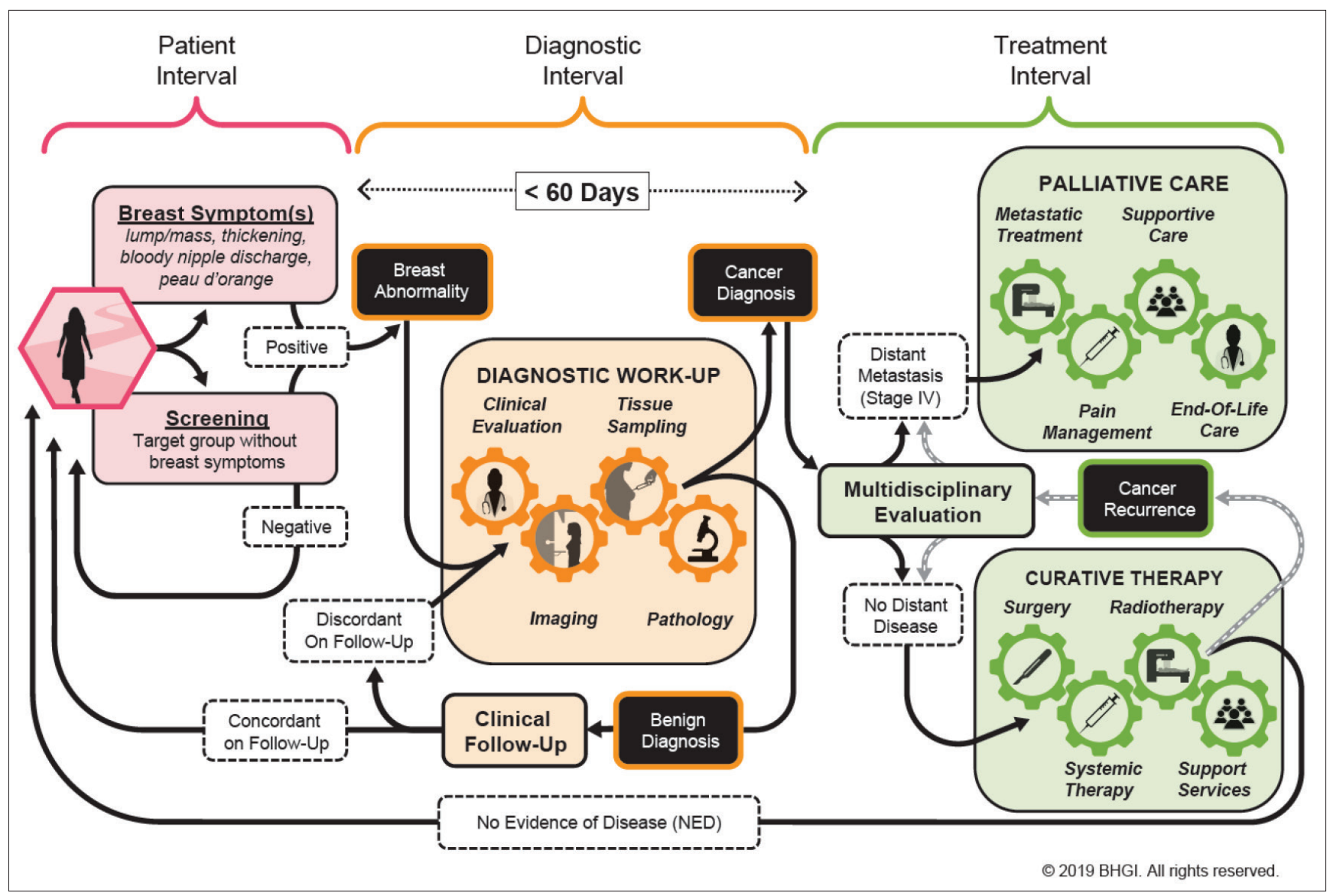

Figure 11. The three sequential episodes of breast cancer management (21)

detection involving breast awareness and clinical breast examination, linked to an integrated treatment strategy, must be organized (25). Moreover, in HIC, the harm-benefit balance must be considered and the fact that increasingly efficient therapies affect this balance. What is important is finding a screening technology that reduces the incidence rates of advanced-stage breast cancers and interval cancer rates as suggested by Philippe Autier during the "San Antonio Breast Cancer Conference 2020" (26).

The annual breast cancer mortality is currently projected to an increase of $33 \%$ by 2040 . If we can reduce breast cancer mortality by $2.5 \%$, more than 2.5 million lives will be saved by 2040 . To achieve this, a global and integrated breast cancer management is proposed by the BHGI (Figure 11).

Neoliberal practices have given people some freedom in choosing their own doctors, shorter waiting times, and better facilities. It is comprised of three principles: individualism, free market, and decentralization. However, the privatization of the healthcare left $15 \%$ of Americans without healthcare, creating inequality in the quality of care between rich and poor. A proper partnership between the public and private sector with the participation of the government in healthcare must be advocated in most countries (27). Accountability mechanisms are needed for all bodies: public, private, national and international (28).

\section{Conclusion}

Recommendations for Better Breast Cancer Care (Video 2)

Video Link 2: https://www.youtube.com/watch?v=9-8klLNTeLE

Cancer registries provide insight into the burden and management of cancer. They are essential to monitor the effectiveness of health system in managing the disease and advise the authorities regarding taking appropriate measures.

Breast cancer care requires integrated teams meeting regularly and having a clinical leader within a breast unit. Multidisciplinary meetings represent a central component of breast care. Tele-oncology can be helpful, but it requires efficient preparation and technological support.

Although prevention is key with a focus on reduction in alcohol and increasing physical activities, early diagnosis remains the most important, and awareness in LMIC and screening in high-income countries (HIC) are even more important.

Quality management must be integrated into daily practice with guideline discussions and monitoring of quality indicators to control the adherence. Identification of minimal and essential requirements can help optimize care delivery with the help of existing financial and personnel resources.

Bringing value-based healthcare to patients can be obtained by putting the patient in the center. The patients should be provided with the best possible treatment ensuring that the perspective of value is captured. All 
players in the field, including policymakers, providers, pharmaceutical industry, information technology providers, and payers, must try optimizing the decision making ensuring the highest value is brought to the patients. Innovations must be rewarded appropriately to the real added value. The the International Consortium for Health Outcomes Measurements initiative puts forward how value-based healthcare can be provided to breast cancer patients.

Continuous education must be provided, and the shortage of workforce, especially the primary care specialists and nurses, should be addressed. In LMIC much effort must be put trying to motivate highly educated care providers staying in their own country.

Accessibility and health coverage must be obtained for all patients. The minimally required essential cancer medicines published by the World Health Organization can help governments in making difficult decisions about the availability of essential breast cancer drugs.

Some recommendations may conserve resources, such as defining and avoiding overtreatment and overdiagnosis, reducing inefficiencies and simplify the treatments, and personalizing the follow-up based on risk of recurrence. Encouraging early diagnosis will increase the chances of survival, and the overall cost will be lower. Promoting evidence-based medicine with the personalization of the treatment, organizing breast care in networks with wellorganized breast units guided by locally appropriate guidelines, encouraging widespread use of ambulatory care, and organizing quality management with a reduction in the administrative burden are recommended.

In LMIC, discussing a cancer plan is especially important. In addition, healthcare networks and health coverage must protect patients against a financial catastrophe. Social health insurance programs are important in LMIC and HIC.

In the future, a new research model must be followed with strong collaboration between academia, pharmaceutical industry, nonacademic centers, and patient coalitions, considering the practical clinical benefit of new treatments.

\section{Acknowledgement}

The authors thank Professor Benjamin Anderson (Breast Health Global Initiative, BHGI) for critical appraisal of this manuscript.

Peer-review: Externally peer-reviewed.

\section{Authorship Contributions}

Conception: D.V., C.A., C.K., S.S., M.J., E.B., M.M.C.; Design: D.V., C.A., C.K., S.S., M.J., E.B., M.M.C.; Supervision: D.V., C.A., C.K., S.S., M.J., E.B., M.M.C.; Materials: D.V., C.A., C.K., S.S., M.J., E.B., M.M.C.; Data Collection or Processing: D.V., C.A., C.K., S.S., M.J., E.B., M.M.C.; Analysis or Interpretation: D.V., C.A., C.K., S.S., M.J., E.B., M.M.C.; Literature Search: D.V., C.A., C.K., S.S., M.J., E.B., M.M.C.; Writing: D.V., C.A., C.K., S.S., M.J., E.B., M.M.C.; Critical Review: D.V., C.A., C.K., S.S., M.J., E.B., M.M.C.

Conflict of Interest: The authors disclose no potential conflicts of interest.

Financial Disclosure: The authors declared that this study received no financial support.

\section{References}

1. Verhoeven D, Kaufman C, Mansel R, Siesling S, editors. Breast cancer: global quality care. Oxford: Oxford University Press; 2020. [Crossref]

2. Verhoeven D, Allemani C, Kaufman C, Mansel R, Siesling S, Anderson B. Breast Cancer: global quality care optimizing care delivery with existing financial and personnel resources. ESMO Open 2020; 4(Suppl 2): e000861. (PMID: 32895233) [Crossref]

3. Piana R. Comprehensive overview of how to start or improve a breast cancer unit on the global stage. Available from: https://ascopost.com/ issues/june-10-2020/comprehensive-overview-of-how-to-start-orimprove-a-breast-cancer-unit-on-the-global-stage/ [Crossref]

4. Allemani C, Matsuda T, Di Carlo V, Harewood R, Matz M, Nikšić $\mathrm{M}$, et al. Global surveillance of trend in cancer survival 2000-2014 (CONCORD-3) analysis of individual records for 37513025 patients diagnosed with one of 18 cancers from 322 population-based registries in 71 countries. Lancet 2018; 391: 1023-1107. (PMID: 29395269) [Crossref]

5. Harlan L, Warren JL. Global survival patterns: potential for cancer control. Lancet 2015; 385: 926-928. (PMID: 25467589) [Crossref]

6. Organisation for Economic Co-operation and Development. Health at a Glance 2020. OECD indicators. Paris, France: OECD Publishing 2020 [Crossref]

7. Biganzoli L, Cardoso F, Beishon M, Cameron D, Cataliotti L, Coles CE, et al. The requirements of a specialist breast centre. Breast 2020; 51: 6584. (PMID: 32217457) [Crossref]

8. Porter M, Teisberg E. Redefining health care. Boston: Harvard Business School Press; 2006. [Crossref]

9. Spronk P, van Bommel A, Siesling S, Wouters MWJM, Vrancken Peeters MTFD, Smorenburg CH. Variation in use of neoadjuvant chemotherapy in patients with stage III breast cancer. Results of the Dutch national breast cancer audit. Breast 2017; 36: 34-38. (PMID: 28942098) [Crossref]

10. Ong W, Schouwenburg M, van Bommel A, Stowell C, Allison KH, Benn KE, et al. A standard set of value-based patient-centered outcomes for breast cancer: the International Consortium for Health Outcomes Measurements (ICHOM) initiative. JAMA Oncol 2017; 3: 677-685. (PMID: 28033439) [Crossref]

11. Kaufman CS. Increasing role of oncoplastic surgery for breast cancer. Curr Oncol Rep 2019; 21: 111. (PMID: 31838584) [Crossref]

12. Bau I, Logan R. Patient-centered, integrated health care quality measures could improve health literacy, language access and cultural competence. 2019 NAM Perspecives. Discussion Paper. Washington: National Academy of Medicine; 2019. [Crossref]

13. Luengo-Fernadez R,Leal J, Gray A, Sullivan R. Economic burden of cancer across the European Union: a population-based cost analysis. Lancet Oncol 2013; 14: 1165-1174. (PMID: 24131614) [Crossref]

14. Hofmarcher T, Lindgren P, Wilking N, Jönsson B. The cost of cancer in Europe 2018. Eur J Cancer 2020; 129: 41-49. (PMID: 32120274) [Crossref]

15. Kimman M, Jan S, Yip CH, Thabrany H, Peters SA, Bhoo-Pathy N, et al. Catastrophic health expenditure and 12-month mortality associated with cancer in Southeast Asia: result from a longitudinal study in eight countries. BMC Med 2015; 13: 190. (PMID: 26282128) [Crossref]

16. Maudgil DD. Cost-effectiveness and the role of the National Institute of Health and Care Excellence (NICE) in interventional radiology. Clin Radiol 2021; 76: 185-192. (PMID: 33081990) [Crossref]

17. Ragavan S, Vanni A. Can international patent law help mitigate cancer inequity in LMICs? AMA J Ethics 2020; 22: E102-E111. (PMID: 32048580) [Crossref]

18. World Trade Organization. Declaration on the TRIPS agreement and public health. 4th WTO Ministerial Conference; November 9-14,2001; 


\section{Eur J Breast Health 2021; 17(2): 86-94}

Doha, Qatar. Last Accessed Date: 11.12.2019. Available from: https:// www.wto.org/english/thewto_e/minist_e/min01_e/mindecl_trips_e. htm. [Crossref]

19. Lo J, Park Y,Sinha R, Sandler DP. Association between meat consumption and risk of breast cancer: findings from the sister study. Int J Cancer 2019; 146: 2156-2165. (PMID: 31389007) [Crossref]

20. Beers E. Information for rational drug prescribing to older patients: availability and applicability. University of Utrecht, Doctoral Thesis. 2014. [Crossref]

21. Chen A, Eljanne M, Harris L, Malik S, Seibel NL. National Cancer Institute basket/umbrella clinical trials: $\mathrm{MATCH}$, lungMAP, and beyond. Cancer J 2019; 25: 272-281. (PMID: 31335391) [Crossref]

22. Aapro M, Astier A, Audisio R, Ian Banks I, Bedossa P, Brain E, et al. Identifying critical steps towards improved access to innovation in cancer care: a European CanCer Organisation position paper. Eur J Cancer 2017; 82: 193-202. (PMID: 28692951) [Crossref]

23. Anderson B, Cazap E, El Saghir N, Yip C-H, Khaled HM, Otero IV, et al. Optimisation of breast cancer management in low-resource and middle resource countries: executive summary of the Breast health global Initiative consensus 2010 Lancet Oncol 2011; 12: 387-398. (PMID: 2146383) [Crossref]
24. Duggan C, Dvaladze A, Rositch AF, Ginsburg O, Yip C-H, Horton S, et al. The breast health global initiative 2018 global summit on improving breast health care through resource-stratified phased implementation: methods and overview. Cancer 2020; 126: 2339-2352. (PMID: 32348573) [Crossref]

25. ACTION Study Group. Policy and priorities for national cancer control planning in low-and middle-income countries: Lessons from the Association of Southeast Asian Nations (ASEAN) Costs in Oncology prospective cohort study. Eur J Cancer 2017; 74: 26-37. (PMID: 28335885) [Crossref]

26. Autier P. Improvements necessary to increase benefits, decrease harms of breast cancer screening. Available from: https://www.sabcsmeetingnews. org/improvements-necessary-to-increase-benefits-decrease-harms-ofbreast-cancer-screening/ [Crossref]

27. Akinci F. Privatization in health care: theoretical considerations and real outcomes. J Econ Econ Educ Res 2002; 3: 62-87. [Crossref]

28. Backman G, Hunt P, Khosla R, Jaramillo-Strouss C, Fikre BM, Rumble C, et al. Health systems and the right to health: an assessment of 194 countries. Lancet 2008; 372: 2047-2085. (PMID: 19097280) [Crossref] 